\title{
What to do when a patient wants to record a patient-physician interaction in the emergency department
}

\author{
Brodie Nolan, $\mathrm{MD}^{*}$; Alun Ackery, MD, MSc* ${ }^{+}$; Bryan Au, $\mathrm{MD}^{*^{\dagger}}$
}

\section{ABSTRACT}

Recent technological advances allow for instantaneous high quality video and audio recordings with the touch of a button. In Canada, patient privacy is highly regulated by provincial legislation, although patients themselves have little in the way of laws or regulations to observe. Patients taking video recordings of their own medical care does not currently fall under any of the provincial privacy laws. With no such governance for the general public, patients generally have greater freedom to record a patient-physician interaction. Unfortunately, there are no official policies from the provincial physician colleges regarding how best to proceed in these circumstances. Therefore, the onus is on individual hospitals and emergency departments (EDs) to develop their own policy on video recordings. A policy should ideally cover possible recording devices, locations, staff involved, and mandate that a written consent form be included with the patient's chart. While every request should be considered individually, physicians should generally not feel compelled to agree to the patient recording the clinical encounter. Patients are legally allowed to record a patient-physician interaction without consent of their physician, because the patient can provide the "one-party consent" for the conversation to be recorded. Physicians should accept the possibility that they are being recorded at all times and should strive to communicate as clearly and effectively as possible. Physicians should strive to provide the same level of care that they would even if they were not being recorded, and not let it interfere with their clinical decision-making.

\section{INTRODUCTION}

You are seeing a new patient in the ED. As you shake hands and introduce yourself to the patient, he pulls out his smartphone, presses a button, and places it down on a table. "Do you mind if I record this, Doc?" he asks. If this has happened to you, rest assured that you are not alone. Smartphones are everywhere. As of $2014,66 \%$ of all Canadians owned a smartphone, growing from $62 \%$ in 2013. ${ }^{1}$ Instantaneous high quality video and audio recordings are now only a swipe or click away. In Canada, patient privacy is highly regulated by provincial legislation, ${ }^{2-10}$ and multiple policies protecting the privacy of patient's personal health information have been published by provincial physician colleges and the Canadian Medical Protective Association (CMPA). Conversely, there is no clear law or regulation for patients in regards to recording their interactions with physicians.

An Internet search demonstrates the breadth of the issue. There are multiple articles promoting the benefits of patients recording their doctor visits and encouraging them to do so to aid in complex decision-making. ${ }^{11}$ News outlets report stories of patients who secretly recorded inappropriate and unbecoming comments from their treating physicians. ${ }^{12}$ Browsing through various medical blogs and physician news media, there appears to be varying opinions when it comes to physicians being recorded by patients, with many opposing the practice. ${ }^{13}$

Audiovisual recordings have been identified as a way of empowering patients to become more engaged in their own medical decision-making. ${ }^{14}$ Another study proposed that recording technology could help advocate for marginalized patients by helping to overcome clinical misperceptions while also holding patients and their physicians accountable. ${ }^{15}$ There is little in the medical literature to provide guidance to physicians on how to best approach these situations. Regarding patients making surreptitious recordings, Rodriguez et al. suggest that the first and most essential strategy entails being aware of and embracing the possibility that every conversation with a patient may be recorded. ${ }^{16}$ Furthermore, they suggest that if you suspect you are being recorded to affirm the benefits of such recordings and educate the patient about the privacy rights of other patients to ensure that there are no violations of patient confidentiality.

From the *Department of Medicine, University of Toronto, Toronto, ON; and the tDepartment of Emergency Medicine, St. Michael's Hospital, Toronto, ON.

Correspondence to: Dr. Bryan Au, St. Michael's Hospital, Department of Emergency Medicine, 30 Bond St., Room 1-008 Shuter Wing, Toronto, ON M5B 1W8; Email: b.au@utoronto.ca 
In this paper, legal and ethical considerations are discussed to provide guidance to Canadian emergency physicians as to how to proceed if a patient requests to record a patient-physician interaction, or if a patient surreptitiously records a patient-physician interaction without consent of the physician. Recommendations for developing an institutional policy on audiovisual recordings are included.

\section{LEGAL CONSIDERATIONS}

Each provincial physician college has a policy regarding physicians making audio or video recordings of patients. ${ }^{17,18}$ In addition, the CMPA has also published guidelines outlining best practices to protect your patient's personal health information. ${ }^{19,20}$ The restrictions on patients recording their own personal health information are far less stringent than those of health care workers. Patients taking video recordings of their own medical care and interactions does not currently fall under any of the provincial privacy laws. ${ }^{21}$ In general, these laws are in place for health information custodians (i.e., health care workers and others employed by a hospital or health care institution) and do not apply to private citizens. ${ }^{2-10}$ With no such governance for the general public, patients generally have greater freedom to record a patientphysician interaction.

The issue of patients making surreptitious recordings came to light recently when an anesthesiologist in the United States was successfully sued after making inappropriate comments about a patient that were recorded on his smartphone while he was under sedation for a colonoscopy. ${ }^{22}$ Although obvious differences exist between the Canadian and American legal systems, the principles of this case hold true for Canadian physicians.

It may surprise many, but patients have no obligation to disclose that they are recording a conversation with their physician. As per the Criminal Code of Canada, ${ }^{23}$ it is not illegal to record a private communication if you are one of the parties involved in the conversation. Specifically, Section 184.2, Subsection 1 states that prohibiting interception (or recording) of private communication does not apply to "a person who has the consent, express or implied, of the originator or person intended by the originator to receive the communication." A patient having a conversation with his or her physician would legally be identified as either an originator or intended person to receive the information, and, because the patient would be able to provide "consent" to the interception as outlined by Section 183.1, that patient would legally be able to surreptitiously record a conversation with his or her physician. This one-party consent has been upheld in many cases before the courts, including R. v. Rosen (1980). ${ }^{24}$ Although we could not find any criminal cases involving patients surreptitiously recording physicians in Canada, it is reasonable to assume that, because these recordings are legally obtained, they could be used as evidence for a malpractice suit or a college complaint.

Currently, the written medical chart acts as the primary record of what happened during a patient's visit to the $\mathrm{ED}$, and its contents are generally viewed as facts by the courts. Although there should be no difference between the written medical chart and any audiovisual recording of a patient-physician interaction, recordings certainly convey more emotional responses. Previous studies have demonstrated the impact of audiovisual evidence altering the perception of defendants. ${ }^{25}$ These responses could influence a judge or jury who finds a physician abrupt, rude, or rushed, and could potentially sway a verdict.

\section{ETHICAL CONSIDERATIONS}

Respect for patient autonomy does not necessarily translate to allowing for patient-physician interactions to be recorded in all cases. If the motivation for recording is improving or enhancing some aspect of the patient's care, then it is likely ethical to consider allowing filming in these circumstances. However, if the motivation is for personal gratification, such as posting to social media, then this extension of autonomy probably does not apply.

As outlined under the principle of beneficence, patients may benefit from recording discharge instructions that they can play back for themselves, for other family members, or for their primary care physician. We know how little patients remember from their time in the ED, and few can recall their discharge or follow-up instructions. ${ }^{26}$

There are, however, important reasons why physicians may not want to be recorded. Physicians, like any other private citizen, have a reasonable expectation to privacy in their workplace. Furthermore, if there is any concern that another patient's personal health information may be captured, then any recording is unacceptable and both the physician and the institution by law cannot permit this. ${ }^{20}$ If one declines to be recorded, and if there is sufficient time, it may be helpful to have a conversation with the patient discussing why you are hesitant to be recorded. 
At the end of the day, physicians act as their own moral agents and have the right to ensure that the care they provide is consistent with their own sense of right and wrong. Although each case must be managed individually, physicians should likely at times be willing to accommodate or find some other way to meet patient needs if there is some benefit to patient care.

\section{PROVINCIAL COLLEGES AND CMPA RECOMMENDATIONS}

Unfortunately, there are no official policies from the provincial physician colleges regarding how to best proceed in these circumstances. Therefore, the bottom line is that it is incumbent upon individual hospitals and clinics to develop their own policy on video recordings in the medical setting.

The CMPA offers the following recommendations: The CMPA recommends the implementation of applicable hospital or clinic policies regarding patients who wish to record part or all of their visit to the hospital or clinic. A policy will clarify the expectations for physicians and their patients. Physicians working in such facilities should be aware of any such policies.

While every request should be considered individually, physicians should generally not feel compelled to agree to the patient recording the clinical encounter. Courts have confirmed that physicians are entitled to refuse such requests unless there is a compelling reason why the recording is necessary. While it is reasonable to probibit patients from recording in public spaces (e.g., waiting room) in the interest of protecting the privacy of others, physicians should consider that there may be legitimate reasons why a patient might wish to record all or parts of a clinical visit (e.g., patient has memory issues or language barriers).

Patients recording their conversations with their physician without the physician's consent is not necessarily probibited by law in Canada. Where a patient expresses an interest in recording all or parts of the clinical encounter, physicians may wish to consider offering to make the recording and to provide the patient with a copy. In any event, the recording might be considered part of the medical record. Therefore, physicians may also consider obtaining a copy for their own medical record, which could also be used in the event of medico-legal difficulties. ${ }^{21}$

\section{DEVELOPING AN INSTITUTIONAL POLICY}

It is essential to seek appropriate expertise from your institution when developing any policy on patient video recording. At our institution, key stakeholders that were involved when drafting the policy on patient video recording included representatives from our privacy office, legal department and counsel, public affairs, and patient affairs offices. A policy should ideally cover all possible recording devices, locations, staff involved, and mandate that a written consent form be included with the patient's chart if consent to recording is granted. Getting input from front-line health care workers from various areas of the hospital (i.e., ED, operating room, labor and delivery) allows for a better appreciation of everyone's concerns and experiences with patients requesting to make recordings. Having a pre-existing institutional policy on video recordings is obviously extremely valuable if an agreement between the physician and the patient cannot be reached. Our own institution's policy on patients making audio and video recordings is presented in Appendix A.

\section{SUMMARY}

Health information privacy laws protect patients, yet physicians have limited legal protection from patients privately recording their interactions. Furthermore, patients are free to choose with whom they share these interactions, and these recordings can easily be taken out of context or shared on social media. A summary of our recommendations is outlined in Figure1.

In the foreseeable future, there are unlikely to be changes to the federal or provincial law regarding patient recordings of encounters with physicians. Therefore, we believe the modern approach to this problem is to simply continue treating the patient and communicating in a professional, exemplary manner. In other words, accept the possibility that you are being recorded at any time. Physicians have always been held to a higher behavioural standard than our patients. As a profession, we should strive to communicate as clearly and effectively as possible. Ensure that your words are chosen carefully and empathetically. If recording is allowed, provide the same level

\footnotetext{
- Be familiar with your ED's policy regarding patients making video recordings.

- If your ED does not have a policy, create one with the input of appropriate stakeholders.

- If you do consent to being recorded, ensure that others' personal health information is protected, and document your consent in the medical record.

- Remember: patients may be recording you at any time, even without your consent.

- Behave in a professional manner at all times.
}

Figure 1. Top 5 Take-home Points 
of care you would as if you were not being recorded, and do not let it interfere with your clinical decision-making.

If you decline to be recorded, if possible, you should offer alternatives to accommodate the patient's wishes to have a record of the interaction. For example, you may offer a clearly written clinical summary or discharge instructions, or offer to allow still pictures before and after suturing a laceration. Having a pre-existing institutional policy on video recordings is obviously extremely valuable if an agreement between the physician and the patient cannot be reached. If you do suspect that you are being recorded, you can ask the patient in a nonconfrontational manner. Take the opportunity to inform them of your institution's recording policy and, most importantly, ensure that other patients' health information privacy is not violated.

\section{CONCLUSION}

It is likely that patients requesting to make audio or video recordings during their $\mathrm{ED}$ visit will become more prevalent. Patients taking video recordings are merely part of the larger picture of patient-centred care in our increasingly technological society. As such, it is important to create an institutional policy, which will cover the making of such recordings. Unfortunately, patients may still make recordings of interactions with their physicians without their knowledge or consent. We believe that continued professionalism, honesty, and excellent communication will serve the physician well in this rare situation.

Competing interests: None declared.

Keywords: audiovisual recordings, smartphones, privacy

\section{SUPPLEMENTARY MATERIAL}

To view supplementary material for this article, please visit https://doi.org/10.1017/cem.2017.23

\section{REFERENCES}

1. Government of Canada. Smartphone and tablet ownership on the rise; 2015. Available at: http://news.gc.ca/web/articleen.do?nid=1018749 (accessed 27 September 2016).

2. Personal Health Information Protection Act. Ontario. General, O Reg 329/04; 2004. Available at: http://canlii.ca/t/ $52 \mathrm{kmr}$ (accessed 9 May 2016).

3. E-Health (Personal Health Information Access and Protection of Privacy) Act. British Columbia. SBC 2008, c 38; 2008. Available at: http://canlii.ca/t/52jf2 (accessed 9 May 2016).
4. Health Information Act. Alberta. RSA 2000, c H-5; 2000 Available at: http://canlii.ca/t/5292d (accessed 9 May 2016).

5. Personal Health Information Act. Manitoba. CCSM c P33.5; 1999. Available at: http://canlii.ca/t/526ht (accessed 9 May 2016).

6. The Health Information Protection Act. Saskatchewan. SS 1999, c H-0.021; 1999. Available at: http://canlii.ca/t/ 52nd5 (accessed 9 May 2016).

7. An Act to amend the Act respecting the protection of personal information in the private sector, Quebec. SQ 2001, c 73; 2001. Available at: http://canlii.ca/t/52nkn (accessed 9 May 2016).

8. Personal Health Information Privacy and Access Act. New Brunswick. SNB 2009, c P-7.05; 2009. Available at: http:// canlii.ca/t/521sf (accessed 9 May 2016).

9. Personal Health Information Act. Newfoundland and Labrador. SNL 2008, c P-7.01; 2008. Available at: http://can lii.ca/t/52h2z (accessed 9 May 2016).

10. Personal Health Information Act. Nova Scotia. SNS 2010, c 41; 2010. Available at: http://canlii.ca/t/52pkj (accessed 9 May 2016).

11. Hsieh P. Why you should record your doctor visits. Forbes; 2015. Available at: http://www.forbes.com/sites/paulhsieh/ 2015/02/16/why-you-should-record-your-doctor-visits/2/ \#61665c013d5c (accessed 27 September 2016).

12. Wang Y. Patient secretly recorded doctors as they operated on her. Should she be so distressed by what she heard? The Washington Post, 7 April 2016. Available at: https://www. washingtonpost.com/news/morning-mix/wp/2016/04/07/ patient-hid-recorder-in-her-hair-as-surgeons-operated-onher-their-words-left-her-deeply-distressed/ (accessed 27 September 2016).

13. Chesanow N. Should patients be permitted to record doctor visits? Medscape; 2015. Available at: http://www.medscape. com/viewarticle/838207 (accessed 27 September 2016).

14. Blumenthal-Barby JS. "That's the doctor's job": overcoming patient reluctance to be involved in medical decision making. Patient Educ Couns 2017;100(1):14-7.

15. Grande SW, Castaldo MG, Carpenter-Song E, et al. A digital advocate? Reactions of rural people who experience homelessness to the idea of recording clinical encounters. Health Expect 2016; epub, doi:10.1111/hex.12492.

16. Rodriguez M, Morrow J, Seifi A. Ethical implications of patients and families secretly recording conversations with physicians. FAMA 2015;313(16):1615-6.

17. College of Physicians and Surgeons of Ontario. Confidentiality of personal health information; 2005. Available at: http://www. cpso.on.ca/Policies-Publications/Policy/Confidentialityof-Personal-Health-Information (accessed 27 September 2016).

18. College of Physicians and Surgeons of British Columbia. Photographic, video and audio recording of patients; 2015. Available at: https://www.cpsbc.ca/files/pdf/PSG-PhotographicVideo-Audio-Recording.pdf (accessed 27 September 2016).

19. Canadian Medical Protective Association. Privacy and confidentiality: consent and the circle of care; 2011. Available at: https://www.cmpa-acpm.ca/web/guest/-/privacy-and-con fidentiality-consent-and-the-circle-of-care (accessed 27 September 2016). 
20. Canadian Medical Protective Association. Technology unleashed - the evolution of online communication; 2012. Available at: https://www.cmpa-acpm.ca/en/web/guest/-/tech nology-unleashed-the-evolution-of-online-communication (accessed 27 September 2016).

21. Personal Communication. Patrick Ceresia, MD. Canadian Medical Protective Association, Chief Privacy Officer and Managing Director, eHealth; 2015.

22. Jackman T. Anesthesiologist trashes sedated patient - and it ends up costing her. The Washington Post; 23 June 2015. Available at: https://www.washingtonpost.com/local/anesthe siologist-trashes-sedated-patient-jury-orders-her-to-pay500000/2015/06/23/cae05c00-18f3-11e5-ab92-c75ae6ab94b5_ story.html (accessed 27 September 2016).
23. Criminal Code, RSC 1985, c C-46; 1985. Available at: http://canlii.ca/t/52hd3 (accessed 27 September 2016).

24. Rosen v. R., [1980] 1 SCR 961, 1979 CanLII 59 (SCC); 1980. Available at: http://canlii.ca/t/1tx99 (accessed 27 September 2016).

25. Heath WP, Grannemann BD. How video image size interacts with evidence strength, defendant emotion, and the defendant-victim relationship to alter perceptions of the defendant. Behav Sci Law 2014;32(4): 496-507.

26. Clarke C, Friedman SM, Shi K, et al. Emergency department discharge instructions comprehension and compliance study. CFEM 2005;7(1):5-11. 